Alma Mater Studiorum - Università di Bologna DEPARTMENT OF ECONOMICS

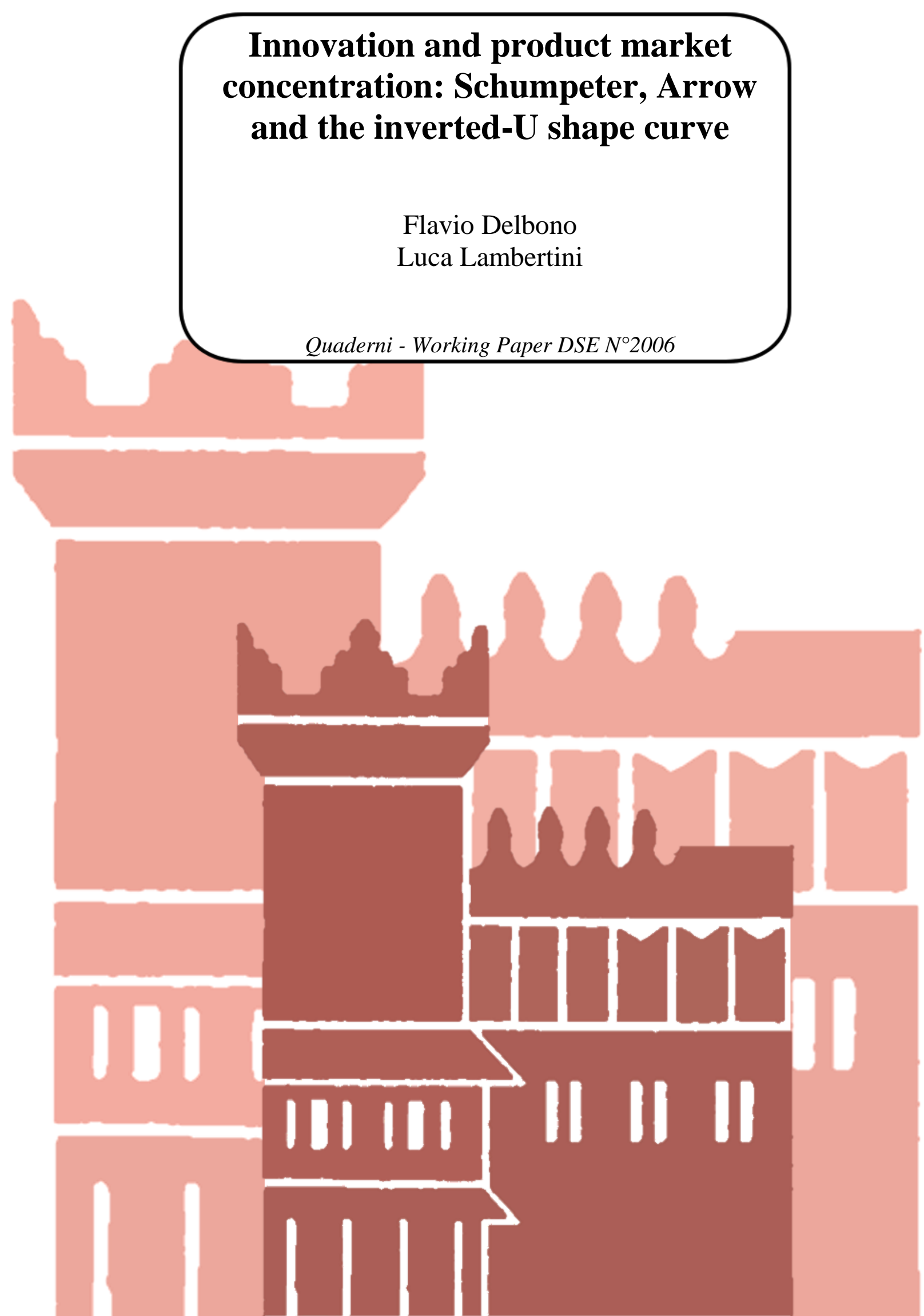




\title{
Innovation and product market concentration: Schumpeter, Arrow and the inverted-U shape curve
}

\author{
Flavio Delbono\# and Luca Lambertini ${ }^{\S}$ \\ Department of Economics, University of Bologna \\ \# Piazza Scaravilli 2, 40126 Bologna, Italy \\ flavio.delbono@unibo.it \\ $\S$ Strada Maggiore 45, 40125 Bologna, Italy \\ luca.lambertini@unibo.it
}

June 5, 2017

\begin{abstract}
We investigate the relationship between market concentration and industry innovative effort within a familiar two-stage model of $R \& D$ race in which firms compete à la Cournot in the product market. With the help of numerical simulations, we show that such a setting is rich enough to generate Arrovian, Schumpeterian and inverted-U curves. We interpret these different patterns on the basis of the relative strength of the technological incentive and the strategic incentive.
\end{abstract}

Keywords: innovation, market structure, aggregate investment JEL Codes: L13, O31 


\section{Introduction}

In a seminal paper, Aghion et al. (2005) collect a robust empirical evidence about the relationship between product market concentration and the intensity of innovative activity. They show that such relationship follows an inverted-U shape pattern with respect to market concentration as measured by an appropriately defined Lerner index. They then go on to rationalize such curve by means of a model in which technologically asymmetric firms strive for improving their cost gap in $\mathrm{R} \& \mathrm{D}$ races under uncertainty. Innovation occur step-by-step and the effect of market competition on R\&D investment results from the balance between what they call the "Schumpeterian" effect and the "escaping competition" incentive.

Aghion et al. (2005) have then revitalized the old debate about the relationship between market structure and innovation. Such debate (see Reinganum, 1989, for an excellent survey) was mostly focussed on a binary menu contrasting the arguments behind Schumpeter (1942) well-known alleged superiority of monopoly in driving innovative activity and the opposite conclusion by Arrow (1962). By showing that the relationship may exhibit an inverted-U shape, they provide an important empirical contribution; moreover, their model offers a theoretical frame accomodating such pattern. ${ }^{1}$

In this paper we show that another, arguably simpler model of product market competition and innovation may predict an inverted-U shape curve.

\footnotetext{
${ }^{1}$ On the inverted-U shape relationship, see the empirical evidence collected by Mansfield et al. (1968). To the best of our knowledge, the first scholars hinting at such shape within a theoretical model are Kamien and Schwartz (1976). They "address the reported empirical finding that the rate of innovative activity increases with the intensity of rivalry up to a point, peaks, and declines thereafter with further increase in the competitiveness of the industry" (Kamien and Schwartz, 1976, p. 247). However, they do not explicitly model the $R \& D$ race as a game, and the prize to the winner is independent of the intensity of rivalry.
} 
We borrow from the game-theoretic literature utilized in the '90s and follow Lee and Wilde (1980). However, we do not blackbox - as they do - the nature of market competition, but we model it explicitly as a homogeneous oligopoly à la Cournot. In such a static two-stage game of $\mathrm{R} \& \mathrm{D}$, firms participate in an uncertain race to get a non-drastic cost-reducing innovation which will allow the winner to compete with a cost advantage in the market game. There is no spillover and Cournot competition in the product market allows all (initially identical) firms to be active also in the asymmetric post-innovation noncooperative equilibrium. For sake of tractability, we adopt a linear-quadratic specification of the R\&D technology and the market game of Lee and Wilde (1980) as in Delbono and Denicolò (1991), where it is shown that, under Cournot competition in the product market, ${ }^{2}$ aggregate R\&D may respond both ways to increases in market concentration. However, the large number of parameters prevents us from deriving clear-cut analytical conclusions as for the existence of an inverted-U shape relationship. Hence, we resort to numerical simulations and show the emergence of such a shape. Moreover, albeit simple, our model is rich enough to generate also an Arrovian as well as a Schumpeterian behaviour in the relationship between aggregate $\mathrm{R} \& \mathrm{D}$ effort and the numerosity of firms.

Specifically, it turns out that, for a given market size, if the innovation is non-drastic:

1. A low productivity of the R\&D technology (and/or a high level of the discount rate) yields a Schumpeterian relationship, e.g. the equilibrium aggregate R\&D effort reaches its peak under monopoly and then monotonically decreases with the number of firms. This holds irrespective of the size

\footnotetext{
${ }^{2}$ The first attempt of modelling the market game as a Cournot one to investigate the relationship between innovation and concentration is Horowitz (1963); see also Scherer (1965, 1967). Stewart (1983) drops the "winner-takes-all" assumption in the Lee and Wilde's model, but he does not model explicitly the market game.
} 
of the innovation.

2. When the productivity of the R\&D technology is high (and/or the level of the discount factor is low), then two scenarios emerge, depending on the magnitude of the cost reduction reached by the winning firm.

2a. If such a reduction is small w.r.t. the given market size, then we detect an inverted-U shape curve between aggregate $R \& D$ and the number of firms.

$2 \mathrm{~b}$. If the cost reduction is large - making the innovation almost drastic - then we observe an Arrovian pattern, e.g., the aggregate investment monotonically grows with the number of firms.

The paper is organized as follows. In section 2 we set the background. In section 3 we specialise the general model and summarize the findings from a large number of numerical simulations by providing some intuition behind different patterns. Section 4 concludes.

\section{The background}

Consider $n$ identical firms investing in $\mathrm{R} \& \mathrm{D}$ to be first in getting a technological improvement. Firms act noncooperatively and choose an investment expenditure $x$ to maximise the discounted stream of expected profits. Technological uncertainty is of the exponential type, i.e., the discovery time is described by an exponential (or Poisson, or 'memoryless') distribution function. Firm $i=1,2, \ldots n$ then maximises the following payoff

$$
\Omega_{i}=\int_{0}^{\infty} e^{-(r+H) t}\left[h\left(x_{i}\right) V_{i}+H_{i} v_{i}+\pi_{i}-x_{i}\right] d t
$$

where $r>0$ is the common discount rate, $h\left(x_{i}\right)$ is $i$ 's hazard rate (i.e., the instantaneous probability of innovating conditional upon not having innovated before), $H=\sum_{i=1}^{n} h\left(x_{i}\right), H_{i}=H-h\left(x_{i}\right), \pi_{i}$ are $i$ 's current gross profits, $V_{i}\left(v_{i}\right)$ is the discounted continuation value of the game if $i$ wins 
(loses) the race. This is the formulation of Lee and Wilde (1980) which modifies Loury's (1979) as for the specification of the R\&D cost. Here, they are non-contractual, that is, a fixed rate of spending $x_{i}$ until a firm succeeds.

As for the hazard function, it is assumed that it is strictly concave, $h(0)=$ $0=\lim _{x_{i} \rightarrow \infty} h^{\prime}\left(x_{i}\right)$ and $\lim _{x_{i} \rightarrow \infty} h^{\prime}\left(x_{i}\right)=\infty$. These are the so-called Inada conditions ensuring the existence of an interior solution and the satisfaction of the second order condition.

The specification of the nature of the $\mathrm{R} \& \mathrm{D}$ cost matters as for the comparative statics properties of the model. Indeed, while Loury (1979) proves that, in the Nash equilibrium, the optimal individual R\&D effort decreases in the number of firms, Lee and Wilde (1980) prove the opposite. ${ }^{3}$

Slightly later, a parallel debate started on the relationship between market power and the incentive to get an exogenous innovation, with Gilbert and Newbery $(1982,1984)$ and Reinganum (1983), reaching opposite conclusions about the persistence of monopoly. This discussion echoes the old dichotomy between Schumpeter (1942) and Arrow (1962). The subsequent literature focusses on the impact of industry structure or the intensity of competition (e.g., Bertrand vs Cournot) for a given market structure on the aggregate investment in R\&D, and is accurately accounted for in Tirole (1988) and Reinganum (1989), inter alia. On the basis of the original contraposition between Schumpeterian and the Arrovian views, the main concern dealt with

3'In Loury's (1979) formulation, the firm's maximand is:

$$
\Omega_{i}=\int_{0}^{\infty} e^{-(r+H) t}\left[h\left(x_{i}\right) V_{i}+H_{i} v_{i}+\pi_{i}\right] d t-x_{i}
$$

where $x_{i}$ is a lump-sum paid by firm $i$ at the outset. "The intuition behind these conclusions is simple. In the Dasgupta and Stiglitz (1980) and Loury model, an increase in the number of firms reduces the expected benefit to investment... leaving expected costs unchanged. The firm responds by reducing investment. In the Lee and Wilde model, both expected benefits and expected costs are reduced by the addition of another firm... and the net effect is to enhance incentives to invest" (Reinganum, 1984, p. 62). 
the sign of the monotonicity of the aggregate innovative effort w.r.t. industry structure. Aghion et al. (2005), instead, show the emergence of a concave and single-peaked relationship from the data and rationalise it with a theoretical model.

In this paper, we aim at showing that the early approach using stochastic race models along the lines of Loury (1979), Dasgupta and Stiglitz (1980), Lee and Wilde (1980) and Reinganum (1983) may indeed generate both monotone patterns as well as the inverted-U shape one.

To do so, we make a further step by specifying the nature of prizes in the race, following Delbono and Denicolò (1991) who consider firms striving for a non drastic cost-reducing innovation and Cournot competition in the market game. The expected stream of discounted profits for firm $i$ becomes:

$$
\Omega_{i}=\frac{h\left(x_{i}\right) \pi_{W}^{*} / r+H_{i} \pi_{L}^{*} / r+\pi^{C}-x_{i}}{r+H_{i}+h\left(x_{i}\right)}
$$

where $\pi_{W}^{*}$ is the instantaneous profit accruing forever to the winner of the $\mathrm{R} \& \mathrm{D}$ race, $\pi_{L}^{*}$ is the instantaneous profit accruing forever to each loser, and $\pi^{C}$ is the instantaneous profit in the pre-innovation symmetric Cournot equilibrium. In the symmetric equilibrium, the following condition must hold: $\frac{\left(\pi_{W}^{*}-\pi_{L}^{*}\right)(n-1) h\left(x_{i}\right) h^{\prime}\left(x_{i}\right)}{r}+\left(\pi_{W}^{*}-\pi^{C}\right) h^{\prime}\left(x_{i}\right)-r-n h\left(x_{i}\right)+x h^{\prime}\left(x_{i}\right)=0$

It can be shown (Beath et al., 1989; and Delbono and Denicolò, 1990) that the equilibrium $\mathrm{R} \& \mathrm{D}$ effort is increasing in both $\pi_{W}^{*}-\pi^{C}$ and $\pi_{W}^{*}-\pi_{L}^{*}$. Let us label the former as technological incentive and the latter as strategic incentive. Notice that $\pi_{W}^{*}-\pi^{C}$ is the difference between the profit of the winner and the current profit. Such a difference captures what has been called the 'profit incentive' by Beath et al. (1989), the 'stand alone incentive' by Katz and Shapiro (1987) and it is related to - but it doesn't coincide with the 'replacement effect' in Fudenberg and Tirole (1986) who follow Arrow's (1962) expression. 
On the other hand, $\pi_{W}^{*}-\pi_{L}^{*}$ is the difference in profits between winning and losing the race, and it captures what has been named as the 'competitive threat' by Beath et al. (1989), the 'incentive to pre-empt' by Katz and Shapiro (1987) and the 'efficiency effect' by Fudenberg and Tirole (1986) and Tirole (1988).

From the standpoint of the debate inaugurated by Aghion et al. (2005), ${ }^{4}$ we can single out an elementary property of the aggregate R\&D effort which was first underlined in Delbono and Denicolò (1991, p. 959). Writing the individual symmetric equilibrium effort as $x^{*}(n)$, we clearly have

$$
\frac{\partial\left(n x^{*}(n)\right)}{\partial n}=x^{*}(n)+n \cdot \frac{\partial x^{*}(n)}{\partial n}=x^{*}(n)\left[1+\frac{n}{x^{*}(n)} \cdot \frac{\partial x^{*}(n)}{\partial n}\right]
$$

which, if $\partial x^{*}(n) / \partial n<0$, may be nil for some $n$ (possibly more than once, as the expression in square brackets will not be linear w.r.t. $n$, in general). This amounts to saying that $\partial x^{*}(n) / \partial n<0$ is a necessary (but not sufficient) condition for the arising of inverted U's. This fact could have triggered a deeper investigation of the relationship between aggregate effort and market structure in the vein of the debate between Schumpeter (1942) and Arrow (1962), possibly spotting a non-monotone behaviour as in Aghion et al. (2005). If this idea had emerged at the time, one should have tried to sign the following expression:

$$
\frac{\partial^{2}\left(n x^{*}(n)\right)}{\partial n^{2}}=2 \cdot \frac{\partial x^{*}(n)}{\partial n}+n \cdot \frac{\partial^{2} x^{*}(n)}{\partial n^{2}}
$$

In (5), the sign of $\partial x^{*}(n) / \partial n$ was established, on the basis of various specifications of the model. ${ }^{6}$ Conversely, the sign of $\partial^{2} x^{*}(n) / \partial n^{2}$ has never been discussed, as (5), in itself, was not considered.

\footnotetext{
${ }^{4}$ See Aghion et al. (2015) for an updated account of such a debate.

${ }^{5}$ Wherever useful, we follow this literature by treating $n$ as a continuous variable.

${ }^{6}$ If the winner takes all, under contractual R\&D costs as in Loury (1979) and Dasgupta and Stiglitz (1980), the sign is negative. Therefore, in their setting, one might have envisaged a peak in industry effort w.r.t. concentration, because (4) may vanish for some values of $n$. Under non-contractual costs, as in Lee and Wilde (1980), it is positive; under
} 
What we are setting out to do in the remainder of the paper is to specify all of the components of (2) as in Delbono and Denicolò (1991) to show the arising of both Schumpeterian and Arrovian patterns of aggregate $R \& D$ as well as an inverted-U shaped curve as in Aghion et al. (2005).

\section{The specialised model}

We consider the homogeneous Cournot model with a linear demand $p=a-Q$ and a constant marginal production cost initially equal to $c \in(0, a)$. If one defines the initial market size as $s \equiv a-c$ and the cost reduction as $d \equiv c-c^{*}$, where $c^{*}$ is the new marginal cost patented by the winner of the $\mathrm{R} \& \mathrm{D}$ race ( $s>d$ because we focus on non-drastic innovation), then the relevant profits to be substituted into (2) are

$$
\pi_{W}^{*}=\frac{(s+n d)^{2}}{(n+1)^{2}} ; \pi_{L}^{*}=\frac{(s-d)^{2}}{(n+1)^{2}} ; \pi^{C}=\frac{s^{2}}{(n+1)^{2}}
$$

As for the hazard function, we stipulate that $h\left(x_{i}\right)=2 \mu \sqrt{x_{i}}$, where $\mu$ is a positive parameter measuring the efficiency of $R \& D$ expenditure. In what follows, we consistently use $\theta \equiv \mu / r$ to save on notation.

Given the triple of profits in (6) and the above specification of the hazard function, the first order condition (FOC) taken on (2) w.r.t. $x_{i}$, under symmetry, is

$$
\frac{-\theta(2 n-1) x+\left[2 \theta^{2}(n-1)\left(\pi_{W}^{*}-\pi_{L}^{*}\right)-1\right] \sqrt{x}+\theta\left(\pi_{W}^{*}-\pi^{C}\right)}{[2 n \theta \sqrt{x}+1]^{2} \sqrt{x}}=0
$$

which yields:

$x_{ \pm}=\frac{\Phi+2 \theta^{2}\left[\pi_{W}^{*}+2(n-1) \pi_{L}^{*}-\Psi\right] \pm \Xi \sqrt{\Phi+4 \theta^{2}\left[\Psi+n \pi_{W}^{*}+(n-1) \pi_{L}^{*}\right]}}{2 \theta^{2}(2 n-1)^{2}}$

non-contractual R\&D costs and Cournot competition, as in Delbono and Denicolò (1991), the sign may change. 
where $\Psi \equiv(2 n-1) \pi^{C}, \Phi \equiv 1+4 \theta^{4}(n-1)^{2}\left(\pi_{W}^{*}-\pi_{L}^{*}\right)^{2}$ and $\Xi \equiv 1-$ $2 \theta^{2}(n-1)\left(\pi_{W}^{*}-\pi_{L}^{*}\right)$. Notice that

$$
\operatorname{sign}\left(x_{+}-x_{-}\right)=\operatorname{sign}(\Xi)
$$

and $\Xi=0$ at

$$
\theta_{ \pm}= \pm \sqrt{\frac{n+1}{2 d(n-1)[2 s+d(n-1)]}}
$$

which, considering that $\theta>0$, implies

$$
\begin{aligned}
\Xi>0 \forall \theta \in\left(0, \theta_{+}\right. & \left.\equiv \sqrt{\frac{n+1}{2 d(n-1)[2 s+d(n-1)]}}\right) \\
\Xi & <0 \forall \theta>\theta_{+}
\end{aligned}
$$

Before proceeding, it is worth noting that $\lim _{n \rightarrow 1} \theta_{+}=\infty, \lim _{n \rightarrow \infty} \theta_{+}=0$, $\partial \theta_{+} / \partial n<0$ and $\partial^{2} \theta_{+} / \partial n^{2}>0$. That is, (i) $\theta_{+}$is decreasing and convex in $n$; (ii) in monopoly, $\Xi>0$ surely; and finally (iii) under perfect competition, $\Xi<0$ surely.

Since the numerator of the expression on the l.h.s. in (7) is concave in $x$, the foregoing analysis proves

Proposition $1 x^{*}=\max \left\{x_{-}, x_{+}\right\}$is the equilibrium individual R\&DD effort, with

$$
\begin{gathered}
\max \left\{x_{-}, x_{+}\right\}=x_{+} \forall \theta \in\left(0, \theta_{+}\right) \\
\max \left\{x_{-}, x_{+}\right\}=x_{-} \forall \theta>\theta_{+}
\end{gathered}
$$

This Proposition, in combination with the limit properties of $\theta_{+}$, entails that when $n=1$, the relevant $\mathrm{R} \& \mathrm{D}$ effort is $x_{M}^{*}=\left.x_{+}\right|_{n=1}$; if instead $n$ becomes infinitely large, the equilibrium $R \& D$ effort is $\lim _{n \rightarrow \infty} x_{-}$.

We are now in a position to assess the impact of industry structure on the aggregate R\&D effort. 


\subsection{Schumpeter, Arrow, and inverted-U's}

Define the aggregate equilibrium investment as $X^{*}=n x^{*}$. Despite the use of an extremely simplified specification of the model, $X^{*}$ remains highly non linear in $n$, which prevents the analytical treatment of the problem under scrutiny and calls for numerical simulations. ${ }^{7}$ We distinguish two cases, depending on the size of $\theta=\mu / r{ }^{8}$ Hence, what follows lends itself to a twofold interpretation, which can focus either on the productivity of $\mathrm{R} \& \mathrm{D}$ for a given level of impatience, or the opposite. In both scenarios, we set parameter values so that (2) be positive.

Scenario I: $\theta \leq \theta_{+}$In this case, $\mu$ and $r$ are set so as to identify values of $\theta \in\left(0, \theta_{+}\right]$. Hence, by Proposition 1 , aggregate effort is $X_{+}^{*}=n x_{+}$.

First of all, we evaluate the behaviour of $X_{+}^{*}$ w.r.t. $n$ in $n=1$. Were the aggregate effort be increasing in $n$ under monopoly, this would exclude a Schumpeterian pattern. To see that this is not the case, note that the following derivative:

$$
\left.\frac{\partial X_{+}^{*}}{\partial n}\right|_{n=1}=-\frac{6(1+\Lambda)+d \theta^{2}\left[4 d^{2} s \theta^{2}+d\left(8 s^{2} \theta^{2}+3\right)+2 s(8+5 \Lambda)\right]}{4 \theta^{2} \Lambda}
$$

where $\Lambda \equiv \sqrt{1+d(d+2 s) \theta^{2}}$, is clearly negative. Moreover, the limit values of $X_{+}^{*}$ are:

$$
\begin{gathered}
\left.X_{+}^{*}\right|_{n=1}=\frac{d(d+2 s) \theta^{2}+2(1+\Lambda)}{4 \theta^{2}}>0 \\
\lim _{n \rightarrow \infty} X_{+}^{*}=0
\end{gathered}
$$

\footnotetext{
${ }^{7}$ We have performed simulations using the ManipulatePlot device in Wolfram's Mathematica 10.1.

${ }^{8}$ In Delbono and Denicolò (1991), only one solution is considered because attention is focussed on low values of $\theta$, in particular so low that the second-order effects of $R \& D$ efficiency (or impatience, as measured by $r$ ) can be neglected.
} 
These properties, of course, do not exclude a non-monotone behaviour of industry investment in some range of $n$ greater than one but not arbitrarily large. For this reason we switch to numerical simulations, fixing once and for all $s=1$. We have performed simulations using the following parameter constellations:

$$
n \in[1,100] ; d \in[1 / 100,10] ; \theta \in[1 / 100,1]
$$

focussing on cases where $s>d, x_{+}^{*}>0$ and $\Omega_{i}\left(x_{+}^{*}\right) \geq 0$. The qualitative properties of the pattern emerging from this simulation are depicted in Figure 1, displaying a Schumpeterian behaviour of aggregate investment w.r.t. industry structure, as $X_{+}^{*}$ consistently looks decreasing and convex in $n .^{9}$

\footnotetext{
${ }^{9}$ If $\theta=\theta_{+}$, the aggregate industry effort is $n x_{+}^{*}=n x_{-}^{*}$ and its expression is

$$
X^{*}=\frac{d n^{2}(2 s+n d)}{(n+1)^{2}(2 n-1)}
$$
}

which is decreasing and convex in $n$ for all $s>d$. 
Figure 1 The Schumpeterian case

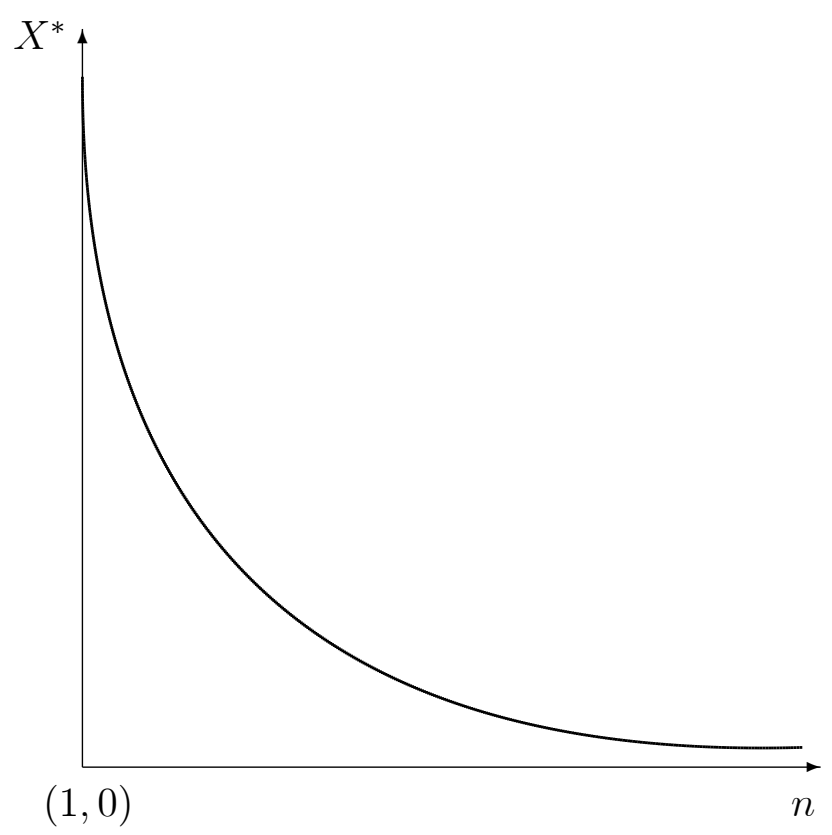

The curve appearing in Figure 1 has been obtained by setting $d=1 / 50$ and $\theta=3 / 2$. These values describe a situation in which the cost reduction is very small and the efficiency of R\&D (time discounting) is very low (high). This amounts to saying that the winner gains a very small profit increase and the remaining $n-1$ firms lose very little as compared to the ex ante symmetric equilibrium. This drives the Schumpeterian outcome.

Some intuition behind the Schumpeterian pattern may rely upon the technological incentive vis à vis the strategic one. A necessary condition for the aggregate effort to be decreasing in $n$ is that $x_{M}^{*}>x_{+}^{*}$, and this inequality certainly holds if both incentives are greater for the monopolist than for the generic oligopolist. Straightforward calculations show that the strategic incentive is always greater for the monopolist, 
whereas the technological incentive is greater for the monopolist when the cost reduction is small.

Scenario II: $\theta>\theta_{+}$In this case, $\mu$ and $r$ are set so as to identify values of $\theta>\theta_{+}$. Hence, by Proposition 1, aggregate effort is now $X_{-}^{*}=n x_{-}$for $n \geq 2$, while $x_{M}^{*}=\left.x_{+}\right|_{n=1}$.

To begin with, observe that

$$
\left.\operatorname{sign} \frac{\partial X_{-}^{*}}{\partial n}\right|_{n=1}=\operatorname{sign} \Upsilon
$$

where

$$
\begin{gathered}
\Upsilon \equiv 6+d \theta^{2}\left[3 d+16 s+4 d s(d+2 s) \theta^{2}\right]- \\
2 \sqrt{1+d \theta^{2}(d+2 s)}\left(3+5 d s \theta^{2}\right)>0
\end{gathered}
$$

This clearly rules out a Schumpeterian pattern, while leaving open both possibilities for an Arrovian behaviour or an inverted-U shape curve. Making ourselves sure again that $s>d, x_{-}^{*}>0$ and $\Omega_{i}\left(x_{-}^{*}\right) \geq 0$, our numerical simulations illustrate that an Arrovian pattern emerges when the cost reduction is large vis à vis market size, whereby the model is close to a 'winner-takes-all' setup, while a concave and single-peaked pattern may obtain if the innovation is small.

The fact that $X_{-}^{*}$ is monotonically increasing in $n$ when $\theta$ is large and the innovation is almost drastic is intuitively due to the fact that, in such a case, the prize to the winner is very close to the pure monopoly profits associated with the new technology. Notice that a sufficient condition to obtain an Arrovian pattern is that both the technological and the strategic incentives are greater for the oligopolist than for the monopolist. Suppose the innovation is drastic $(d=s)$; then, the technological incentive is greater for the oligopolist, whereas the strategic 
incentive is identical across firms. By continuity, if $d$ is lower than $s$ but close to it, also the strategic incentive is greater for the oligopolist. ${ }^{10}$ For instance, keeping $s$ at 1 and taking as a reference set of intervals the following:

$$
n \in[1,100] ; d \in[1 / 100,10] ; \theta \in[1 / 100,100],
$$

one has to take into account the constraint $\theta>\theta_{+}$, which depends on $\{d, n\}$. A pair which surely satisfies this constraint is $\{d=1 / 2, \theta=50\}$ and this generates the Arrovian graph appearing in Figure 2, where the curve starts at $n=2$ and the optimal monopoly effort $\left.x_{+}\right|_{n=1}$ is identified by the flat line.

\section{Figure 2 The Arrovian case}

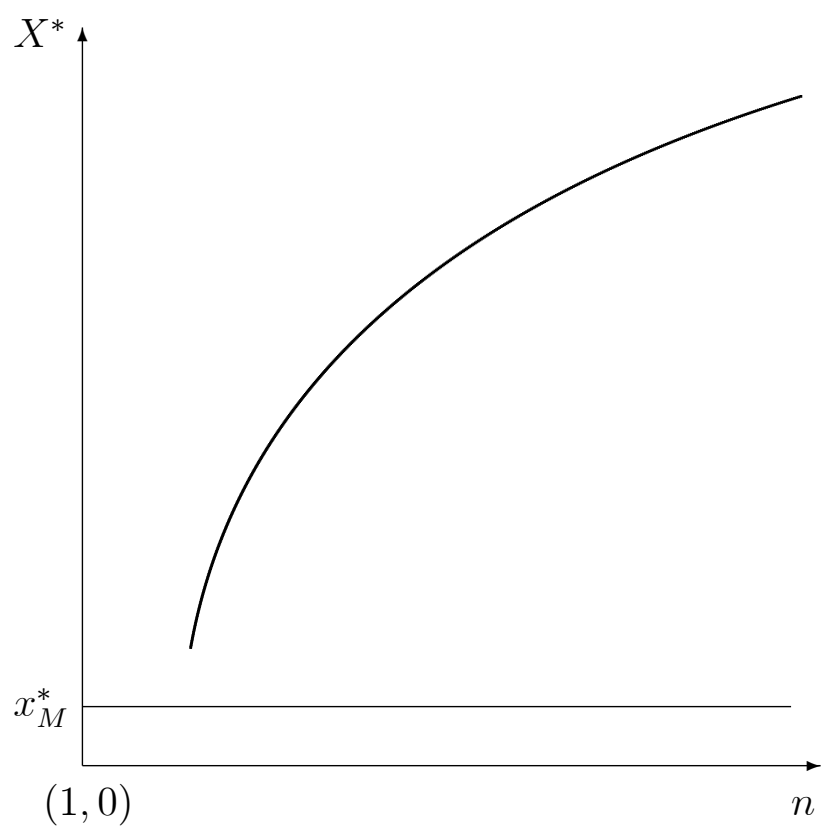

\footnotetext{
${ }^{10}$ Incidentally, this is precisely the setting considered by Reinganum (1983) in her reply to Gilbert and Newbery (1982).
} 
The remaining pattern, which is in Figure 3, reflects the inverted-U shape we know from Aghion et al. (2005). In our setting, such a curve emerges when the cost reduction is very small as compared to market size. Taking as a general reference (17), then fixing $\{d=1 / 100, \theta=50\}$, and accounting for the integer constraint on $n$, the peak of $X_{-}^{*}$ is in correspondence of $n=3$, with $X_{-}^{*} \simeq 0.122$, while $x_{M} \simeq 0.007$.

Figure 3 The inverted-U case

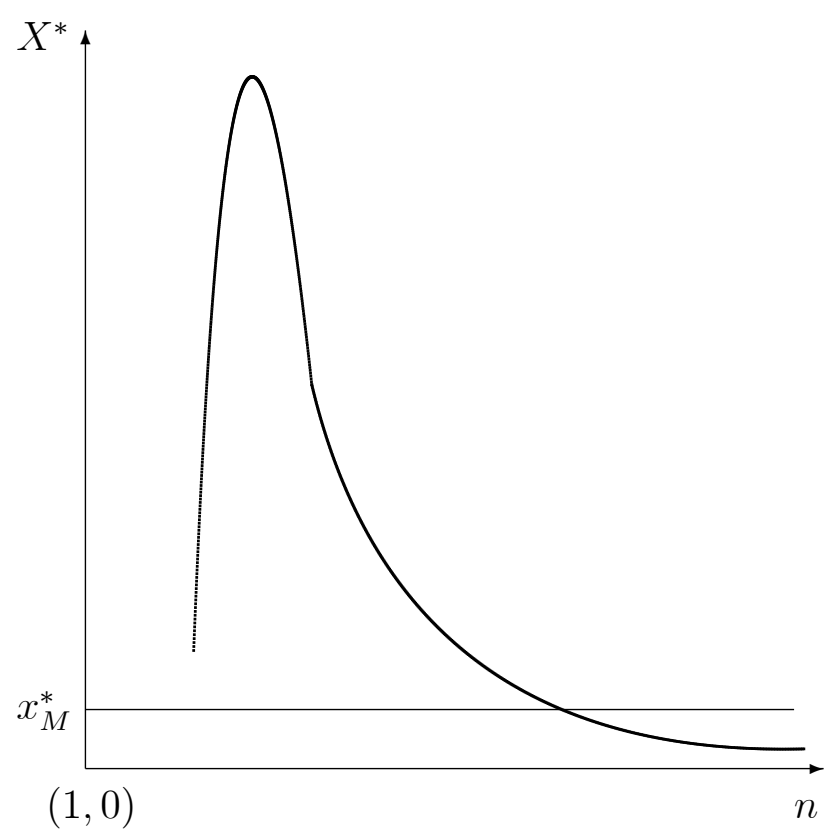

The intuition behind this curve may rely upon the contrast between the small technological gain and the price effect driven by the numerosity of rivals. In a highly concentrated oligopoly, the gain from the R\&D investment (which is highly productive) prevails and the curve looks like the Arrovian one. As market competition intensifies and erodes profits, the opposite applies and the curve slopes downwards as in Schumpeter. 


\section{Concluding remarks}

The long-standing debate about the impact of industry structure on aggregate innovative activity has been revitalised by Aghion et al. (2005) putting in evidence a concave non-monotone behaviour in sharp contrast with Schumpeter (1942) and Arrow (1962). This has triggered a new stream of research aimed at modelling this inverted-U shape relationship emerging from empirical evidence.

We have participated in this research by revisiting the model in Delbono and Denicolò (1991), where a hint in this direction was already suggested. Although the complexity of the model requires resorting to numerical simulation, it is nonetheless true that the conclusions we reach are robust to the specification of parameters and, more importantly, lend themselves to an interpretation in line with the intuition inherited from a well established tradition.

In summary, our findings can be spelled out as follows. If innovations are non-drastic, for a given market size: (i) a Schumpeterian pattern is generated by a low productivity of the R\&D technology, or, equivalently, high discounting, regardless of the innovation size; (ii) the Arrovian and nonmonotone patterns arise when $\mathrm{R} \& \mathrm{D}$ efficiency is high, or discounting is low. The former is driven by large innovations, while the latter by small ones. 


\section{References}

[1] Aghion, P., U. Akcigit and P. Howitt (2015), "The Schumpeterian Growth Paradigm", Annual Review of Economics, 7, 557-75.

[2] Aghion, P., N. Bloom, R. Blundell, R. Griffith and P. Howitt (2005), "Competition and Innovation: an Inverted-U Relationship", Quarterly Journal of Economics, 120, 701-28.

[3] Arrow, K. (1962), "Economic Welfare and the Allocation of Resources for Invention", in R. Nelson (ed.), The Rate and Direction of Inventive Activity, Princeton, Princeton University Press.

[4] Beath, J., Katsoulacos, Y. And D. Ulph (1987), "Sequential Product Innovation and Industry Evolution", Economic Journal (Conference Papers), 97, 32-43.

[5] Dasgupta, P. and J. Stiglitz (1980), "Uncertainty, Industrial Structure, and the Speed of R\&D", Bell Journal of Economics, 11, 1-28.

[6] Delbono, F. and V. Denicolò (1990), "R\&D Investment in a Symmetric and Homogeneous Oligopoly: Bertrand vs Cournot", International Journal of Industrial Organization, 8, 297-313.

[7] Delbono, F. and V. Denicolò (1991), "Incentives to Innovate in a Cournot Oligopoly", Quarterly Journal of Economics, 106, 951-61.

[8] Fudenberg, D. and J. Tirole (1986), Dynamic Models of Oligopoly, London, Harwood.

[9] Gilbert, R. and D. Newbery (1982), "Preemptive Patenting and the Persistence of Monopoly", American Economic Review, 72, 514-26. 
[10] Gilbert, R. and D. Newbery (1984), "Preemptive Patenting and the Persistence of Monopoly: A Comment", American Economic Review, 74, 238-42.

[11] Horowitz, I. (1963), "Research Inclinations of a Cournot Oligopolist", Review of Economic Studies, 30, 128-30.

[12] Kamien, M. and N. Schwartz (1976), "On the Degree of Rivalry for Maximum Innovative Activity", Quarterly Journal of Economics, 90, $245-60$.

[13] Katz, M. and C. Shapiro (1987), "R\&D Rivalry with Licensing or Imitation", American Economic Review, 77, 402-20.

[14] Lee, T. and L. Wilde (1980), "Market Structure and Innovation: A Reformulation", Quarterly Journal of Economics, 94, 429-36.

[15] Loury, G. (1979), "Market Structure and Innovation", Quarterly Journal of Economics, 93, 395-410.

[16] Mansfield, E., J. Rapoport, A. Romeo, E. Villani, S. Wagner and F. Husic (1977), The Production and Application of New Industrial Technologies, New York, Norton.

[17] Reinganum, J. (1983), "Uncertain Innovation and the Persistence of Monopoly", American Economic Review, 73, 741-48.

[18] Reinganum, J. (1984), "Practical Implications of Game Theoretic Models of R\&D", American Economic Review, 74 (Papers and Proceedings), 61-66.

[19] Reinganum, J. (1989), "The Timing of Innovation: Research, Development and Diffusion", in R. Schmalensee and R. Willig (eds), Handbook of Industrial Organization, Amsterdam, North-Holland. 
[20] Scherer, F. (1965), "Firm Size, Market Structure, Opportunity, and the Output of Patented Inventions", American Economic Review, 55, 1097125 .

[21] Scherer, F. (1967), "Research and Development Resource Allocation Under Rivalry", Quarterly Journal of Economics, 81, 359-94.

[22] Schumpeter, J. (1942), Capitalism, Socialism and Democracy, London, Allen \& Unwin.

[23] Stewart, M. (1983), "Noncooperative Oligopoly and Preemptive Innovation without Winner-take-all", Quarterly Journal of Economics, 98, 681-94.

[24] Tirole, J. (1988), The Theory of Industrial Organization, Cambridge, MA, MIT Press. 


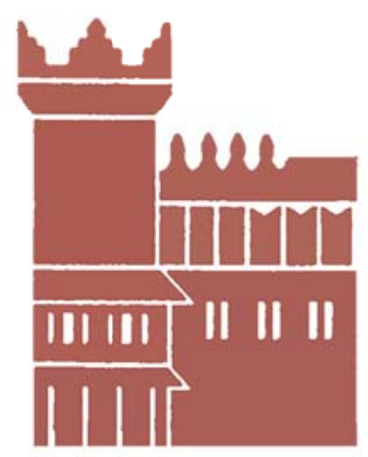

Alma Mater Studiorum - Università di Bologna DEPARTMENT OF ECONOMICS

Strada Maggiore 45

40125 Bologna - Italy

Tel. +39051 2092604

Fax +390512092664

http://www.dse.unibo.it 